\title{
Pioglitazone ameliorates memory deficits in streptozotocin-induced diabetic mice by reducing brain $\beta$-amyloid through PPARy activation
}

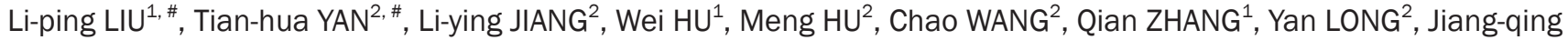 \\ WANG $^{1}$, Yong-qi $\mathrm{LI}^{2}$, Mei HU⿱2${ }^{2}$, Hao HONG ${ }^{2}$, * \\ ${ }^{1}$ Department of Pharmacy, the Second Hospital Affiliated to Anhui Medical University, Hefei 230031, China; ${ }^{2}$ Department of Pharma- \\ cology, China Pharmaceutical University, Nanjing 210009, China
}

\begin{abstract}
Aim: To examine the effects of pioglitazone, a PPARy agonist, on memory performance and brain amyloidogenesis in streptozotocin (STZ)-induced diabetic mice.

Methods: ICR male mice were injected with STZ (150 mg/kg, iv) to induce experimental diabetes. Pioglitazone $\left(9 \mathrm{and}^{18} \mathrm{mg} \cdot \mathrm{kg}^{-1} \cdot \mathrm{d}^{-1}, \mathrm{po}\right)$ was administered for 6 weeks. Passive avoidance and Morris water maze (MWM) tests were used to evaluate cognitive function. The blood glucose and serum insulin levels were detected using the glucose oxidase method and an ELISA assay, respectively. $\beta$-amyloid $(A \beta), \beta$-amyloid precursor protein (APP), $\beta$-amyloid precursor protein cleaving enzyme 1 (BACE1), NF-kB p65, the receptor for advanced glycation end products (RAGE) and PPARy in the brains were analyzed using Western blotting assays.

Results: The STZ-induced diabetic mice characterized by hyperglycemia and hypoinsulinemia performed poorly in both the passive avoidance and MWM tests, accompanied by increased $A \beta_{1-40} / A \beta_{1-42}$, APP, BACE1, NF-KB p65 and RAGE levels and decreased PPARy level in the hippocampus and cortex. Chronic pioglitazone treatment significantly ameliorated the memory deficits and amyloidogenesis of STZ-induced diabetic mice, and suppressed expression of APP, BACE1, RAGE and NF-KB p65, and activated PPARY in the hippocampus and cortex. However, pioglitazone did not significantly affect blood glucose and insulin levels.

Conclusion: Pioglitazone ameliorates memory deficits in STZ-induced diabetic mice by reducing brain A $\beta$ level via activation of PPARY, which is independent of its effects on blood glucose and insulin levels. The results suggest that pioglitazone may be used for treating the cognitive dysfunction in type 1 diabetes mellitus.
\end{abstract}

Keywords: diabetes mellitus; pioglitazone; learning memory; hippocampus; cortex; PPARy; $\beta$-amyloid; BACE1; NF-kB; receptor for advanced glycation end products; APP

Acta Pharmacologica Sinica (2013) 34: 455-463; doi: 10.1038/aps.2013.11; published online 25 Mar 2013

\section{Introduction}

There is substantial evidence that diabetes mellitus (DM) may have a negative impact on the central nervous system, and that cognitive impairment is the most common symptom of this condition ${ }^{[1-3]}$. Hyperglycemia-associated microvascular changes in the brain are responsible for the cognitive decline in patients with type 1 diabetes mellitus (T1DM); intensive insulin therapy for the treatment of T1DM results in improved glycemic control. Additionally, insulin treatment aims toward correcting the deficits in spatial learning and memory ${ }^{[4,5]}$. However, cognitive deficits are almost fully prevented by

\footnotetext{
\#These authors contributed equally to this work.

* To whom correspondence should be addressed.

E-mail haohongchina@hotmail.com

Received 2012-10-18 Accepted 2013-01-02
}

C-peptide (a byproduct of insulin biosynthesis) replacement from the onset of diabetes, but C-peptide has no effect on the blood glucose level ${ }^{[6,7]}$. Thus, diabetes-associated cognitive decline can be influenced by other biomedical factors that are insidiously associated with diabetes.

The impairment of cognitive capacities is reportedly associated with the increasing amount of amyloid plaques and neurofibrillary tangles in the hippocampus at autopsy in diabetes $^{[8-10]}$. Amyloid- $\beta(A \beta)$ accumulation also occurred in the brain of diabetic animals spontaneously ${ }^{[11]}$ or induced by streptozotocin (STZ), a diabetogenic agent, toxic to $\beta$ cells of pancreatic island ${ }^{[12-16]}$. Furthermore, diabetes-accelerated memory dysfunction was due to cerebrovascular inflammation and $A \beta$ deposition in an Alzheimer mouse model with diabetes $^{[17]}$. These findings suggested that $A \beta$ accumulation in the brain in diabetic condition may be one of the important 
reasons for diabetes-associated cognition impairment.

Peroxisome proliferator-activated receptors (PPARs) are ligand-dependent transcription factors. Activation of the PPARY subtype is known to increase insulin sensitization and to modulate glucose and lipid metabolism. Pioglitazone is a thiazoledinedione (TZD) and a highly selective PPARY agonist. It is currently approved as an oral monotherapy and adjunctive therapy for patients with type 2 diabetes mellitus $(\mathrm{T} 2 \mathrm{DM})^{[18]}$. Recently, the focus on PPAR $\gamma$ agonists has intensified because their novel biological roles have emerged, particularly for their therapeutic potential in brain disorders ${ }^{[19]}$. We found in our previous studies that pioglitazone reverses memory impairment in a mouse model with T2DM, which is involved not only in the inhibition of amyloidogenesis in the brain but also in the attenuation of hyperglycemia and hypoinsulinemia in the periphery ${ }^{[20]}$. To date, less attention has been given to the effect of PPARY agonists on the cognitive impairment in T1DM. In this study, we used STZ-induced diabetic mice similar to those with T1DM to observe the effects of pioglitazone on memory deficits and cerebral amyloidogenesis.

\section{Materials and methods \\ Materials}

Pioglitazone was purchased from Jiangsu Hengrui Medicine Co Ltd (Nanjing, China). STZ was purchased from Sigma (St Louis, MO, USA). Mouse antibodies were purchased from different companies: anti-A $\beta_{1-42}$ and anti-receptor for advanced glycation end products (RAGE) were obtained from Abcam Ltd (Hong Kong, China); anti-PPAR, , anti- $\beta$-amyloid precursor protein (APP), anti- $\beta$-site amyloid precursor protein cleaving enzyme 1 (BACE1), and anti-NF-kB p65 were obtained from Cell Signaling Technology, Inc (Boston, MA, USA); anti- $\beta$-actin was obtained from Boster Biotechnology Co, Ltd (Wuhan, China); and secondary antibodies were obtained from Bioworld Technology Co, Ltd (Minneapolis, MN, USA). Mouse $A \beta_{1-40}, A \beta_{1-42}$ and insulin ELISA kits were purchased from Jianglai Biotech Institute (Shanghai, China). The glucose kit and the Coomassie (Bradford) protein assay kit were purchased from Nanjing Jiancheng Biotech Institute (Nanjing, China). All other chemicals were of analytical grade and were commercially available.

\section{Methods}

ICR male mice (aged 8-10 weeks old, weighing 20-25 g) were purchased from Yangzhou University Medical Center (Yangzhou, China). The mice were provided with appropriate food and water, and they were kept under conventional conditions of controlled temperature, humidity, and lighting $\left(22 \pm 2{ }^{\circ} \mathrm{C}\right.$, $55 \% \pm 5 \%$, and a 12-h light/dark cycle with lights on at 7:00 AM). All experiments were performed in accordance with the National Institute of Health Guide for the Care and Use of Laboratory Animals, USA. We produced the STZ-induced hyperglycemic state as an animal model of T1DM by a singletail vein injection of STZ, $150 \mathrm{mg} / \mathrm{kg}$ body weight, freshly dissolved in sodium citrate buffer ( $\mathrm{pH} 4.5)$. We determined the fasting blood glucose (FBG) and serum insulin levels using the glucose oxidase method and an ELISA assay. We confirmed diabetes by the presence of hyperglycemia (>11.0 mmol/L) and insulinopenic conditions. Animals with similar degrees of hyperglycemia and body weight were randomly divided into 3 groups: the STZ plus vehicle group (STZ+Veh), the STZ plus $18 \mathrm{mg} / \mathrm{kg}$ pioglitazone group (STZ+Pio 18) and the STZ plus 9 $\mathrm{mg} / \mathrm{kg}$ pioglitazone group (STZ+Pio 9). Age-matched control mice were injected with the vehicle and divided into 2 groups: the vehicle plus vehicle (Veh+Veh) group and the vehicle plus $18 \mathrm{mg} / \mathrm{kg}$ pioglitazone (Veh+Pio 18) group. Pioglitazone was dissolved in $0.5 \%$ sodium carboxymethyl cellulose (CMC-Na); the total time for oral administration was 6 weeks.

The dosages and time of pioglitazone treatment were designed based on our previous study ${ }^{[20]}$. Body weight was monitored every week. After 5 weeks of pioglitazone treatment, the passive avoidance test and subsequent Morris water maze (MWM) test were carried out to evaluate cognitive function. Following these behavior tests, we measured blood glucose and serum insulin levels using assay kits. The mice were euthanized under ether anesthesia for assays of A $\beta, A P P$, BACE1, NF-кB p65, RAGE, and PPARү in the brain.

\section{Passive avoidance test}

The passive avoidance test is a widely accepted simple and rapid means of testing memory. Passive avoidance response was determined using a "step-through" apparatus (Huaibei Zhenghua Biologic Equipment Co, Ltd, Huaibei, China), which consisted of illuminated and dark compartments (each $32.5 \mathrm{~cm} \times 14 \mathrm{~cm} \times 36 \mathrm{~cm}$ ) adjoining each other via a guillotine door. The floors were constructed of $3.175-\mathrm{mm}$ stainless steel rods set $8 \mathrm{~mm}$ apart. The mice underwent two separate trials: a training trial and a test trial $24 \mathrm{~h}$ later. For the training trial, mice were initially placed in the illuminated chamber. When mice entered the dark compartment, the door closed and an electrical foot shock $(0.4 \mathrm{~mA})$ of $2 \mathrm{~s}$ duration was delivered through the stainless steel rods. One hour before the training trial, mice were administered with pioglitazone $(18 \mathrm{mg} / \mathrm{kg}$ or $9 \mathrm{mg} / \mathrm{kg}$, orally). Control animals received $0.5 \% \mathrm{CMC}-\mathrm{Na}$ rather than pioglitazone. Twenty-four hours after the training trial, mice were placed in the illuminated compartment for the test trial. The time taken for a mouse to enter the dark compartment after the door opening was defined as latency for both training and test trials. Latency to enter the dark compartment was recorded up to $300 \mathrm{~s}$. To avoid a ceiling effect in normal animals, pioglitazone alone was administered $1 \mathrm{~h}$ before the training trial.

\section{Morris water maze test}

Spatial memory was assessed by the Morris water maze (MWM) test, which consisted of a 5 -d training period (visible and invisible platform training sessions) and a probe trial on d 6. This test was carried out as described previously ${ }^{[21]}$ with some modifications. The mice were individually trained in a circular pool $(120 \mathrm{~cm}$ diameter, $50 \mathrm{~cm}$ height) filled with water to a depth of $30 \mathrm{~cm}$ and maintained at $25^{\circ} \mathrm{C}$. The maze was located in a lit room with visual cues. A platform $(9 \mathrm{~cm}$ 
diameter) was placed in the center of one quadrant of the pool. The platform's position was fixed throughout the training sessions; the starting points were pseudo-randomized for each trial, with the animals facing the wall. Each mouse was individually trained in both visible-platform (d 1-2) and hiddenplatform (d 3-5) versions. Visible-platform training was performed for baseline differences in vision and motivation; the platform was placed $1 \mathrm{~cm}$ below the surface of the water and was indicated by a small flag $(5 \mathrm{~cm}$ in height). The hiddenplatform version evaluates spatial learning and determines memory retention in terms of the ability to find the platform. During training, the platform was placed $1 \mathrm{~cm}$ below the surface of the water, and the flag was removed. The platform was always in the same place. On each day, the animal was subjected to four trials with a 1-h interval between trials. Each trial lasted $90 \mathrm{~s}$ unless the animal reached the platform in less time. If an animal failed to find the platform within $90 \mathrm{~s}$, the test was ended and the animal was gently navigated by hand to the platform for $30 \mathrm{~s}$. On d 6, the platform was removed and the probe trial started, during which the animals had $90 \mathrm{~s}$ to search for the platform. The time spent in the target quadrant (ie, the quadrant where the platform was previously located) was recorded. Data of the escape latency and the percentage of time in the target quadrant were collected by the video tracking equipment and processed by a computer equipped with an analysis-management system (Viewer 2 Tracking Software, Ji Liang Instruments, China).

\section{ELISA assay}

For the ELISA assay of the brain tissues, the mice were euthanized by cervical dislocation, and their brains were snapfrozen in dry ice for dissection of the hippocampus and cortex, which were then homogenized; ie, 20\% tissue homogenates were prepared in $0.1 \mathrm{~mol} / \mathrm{L} \mathrm{PBS}, \mathrm{pH} 7.4$, and stored at $-70^{\circ} \mathrm{C}$ until use. All the procedures were performed in accordance with the manufacturer's instructions. The sample $(50 \mu \mathrm{L})$ was added to the precoated plate and incubated for $30 \mathrm{~min}$ at $37^{\circ} \mathrm{C}$ in the dark. After washing each well of the precoated plate with washing buffer, $50 \mu \mathrm{L}$ of labeled antibody solution was added, and the mixture was incubated at $37^{\circ} \mathrm{C}$ in the dark for $30 \mathrm{~min}$. Chromogen was added after washing, and the mixture was incubated at $37^{\circ} \mathrm{C}$ in the dark for $15 \mathrm{~min}$. After the addition of the stop solution, the absorption of the resulting solution was recorded at $450 \mathrm{~nm}$ using a microplate absorbance reader. The protein content was measured using a Coomassie blue-based assay reagent and bovine serum albumin as standards. The results were expressed as micrograms of $A \beta_{1-40}$ and $A \beta_{1-42}$ per gram of protein.

\section{Western blotting}

The mouse hippocampus and cortex were chopped into small pieces and homogenized in $0.5 \mathrm{~mL}$ of RIPA buffer. The dissolved proteins were collected from the supernatant after centrifugation at $12000 \times g$ for $15 \mathrm{~min}$. Protein concentrations were determined using Coomassie blue-based assay reagent, and then the levels of $\mathrm{A} \beta_{1-42}$ APP, BACE1, NF-kB p65, RAGE, and PPARY proteins were determined. Protein extracts were separated by SDS-polyacrylamide gel electrophoresis and then transferred onto a PVDF membrane. The membrane was blocked with 5\% skim milk in Tris-buffered saline and then incubated at $4^{\circ} \mathrm{C}$ overnight with the appropriate primary antibodies for rabbit anti-A $\beta_{1-42}$ (1:500), APP (1:500), BACE1 (1:500), RAGE (1:500), NF-kB p65 (1:500), PPARY (1:500), or $\beta$-actin (inner control, 1:500). After washing with TBST, the membranes were incubated with a horseradish peroxidaseconjugated secondary antibody (1:5000) for $2 \mathrm{~h}$ at room temperature. The antibody-reactive bands were visualized using the enhanced chemiluminescence detection reagents included in a gel imaging system (ChemiScope 2850, Clinx Science Instruments Co, Ltd, Shanghai, China).

\section{Statistical analysis}

The data are expressed as the mean \pm standard error (SEM). All data, unless specified, were analyzed using a one-way ANOVA followed by Newman-Keuls tests for post hoc comparisons between groups. When two factors were assessed, the significance of differences was determined using two-way ANOVAs. $P<0.05$ was considered statistically significant.

\section{Results}

\section{Chronic pioglitazone treatment attenuates memory impairment} in STZ-induced diabetic mice

We first assessed the performance of mice for long-term memory using the passive avoidance task. The latency during the learning trial did not differ among any of the groups (data not shown), indicating that all the mice had similar responses to the testing environment and electric shocks. The retention test $24 \mathrm{~h}$ after the initial training illustrated that STZ-induced diabetic mice demonstrated significant decreases in step-through latency $[F(4,49)=6.957, P<0.001$, Figure $1 \mathrm{~A}]$ and increases in the number of errors $[F(4,49)=6.640, P<0.001$, Figure $1 B]$ compared to those in the age-matched Veh+Veh group. Treating STZ-induced diabetic mice with pioglitazone $(18 \mathrm{mg} / \mathrm{kg}$ and $9 \mathrm{mg} / \mathrm{kg}$ ) demonstrated significant increases in the escape latency $(P<0.01$, Figure $1 \mathrm{~A})$ and decreases in the number of errors $(P<0.05$, Figure $1 B)$ compared to those in $S T Z+V e h$ group.

To confirm the results observed in the passive avoidance task, we carried out the MWM test. The mice in each group exhibited similar escape latency in the 2-d visible-platform test, suggesting that there was no difference in vision or basal motivation among all the groups $[F(4,299)=1.782, P=0.132$, Figure $1 \mathrm{C}]$. We then tested the mice in the 3 -d spatial hiddenplatform variant; the results indicated that the mice in the STZ+Veh group showed increases in escape latencies compared to those in the corresponding controls (Veh+Veh group) $[F(4,399)=5.025, P=0.001$, Figure 1D]; these were reversed by pioglitazone. In the probe trial, a putative measure of spatial learning and memory retention, the swim path (Figure 1F) showed that all the mice demonstrated a preference for the target quadrant, with the exception of the mice in the STZ+Veh group, which displayed a significant decrease in the percent- 

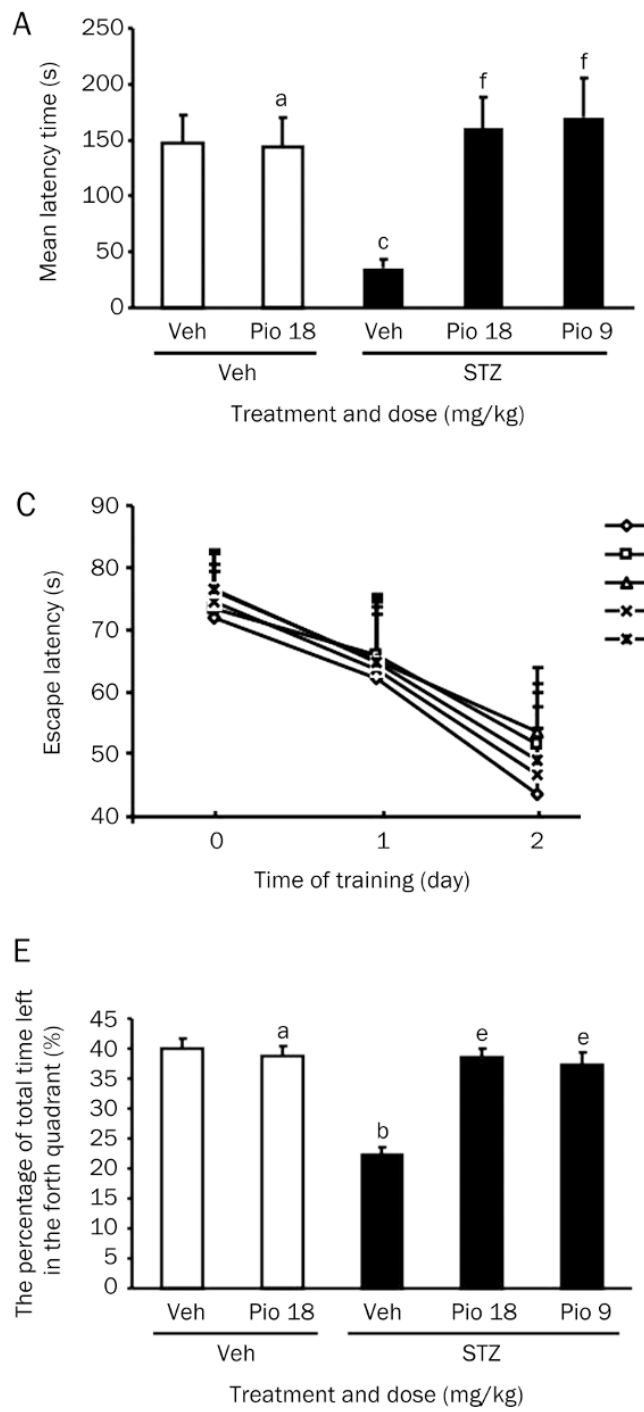

B
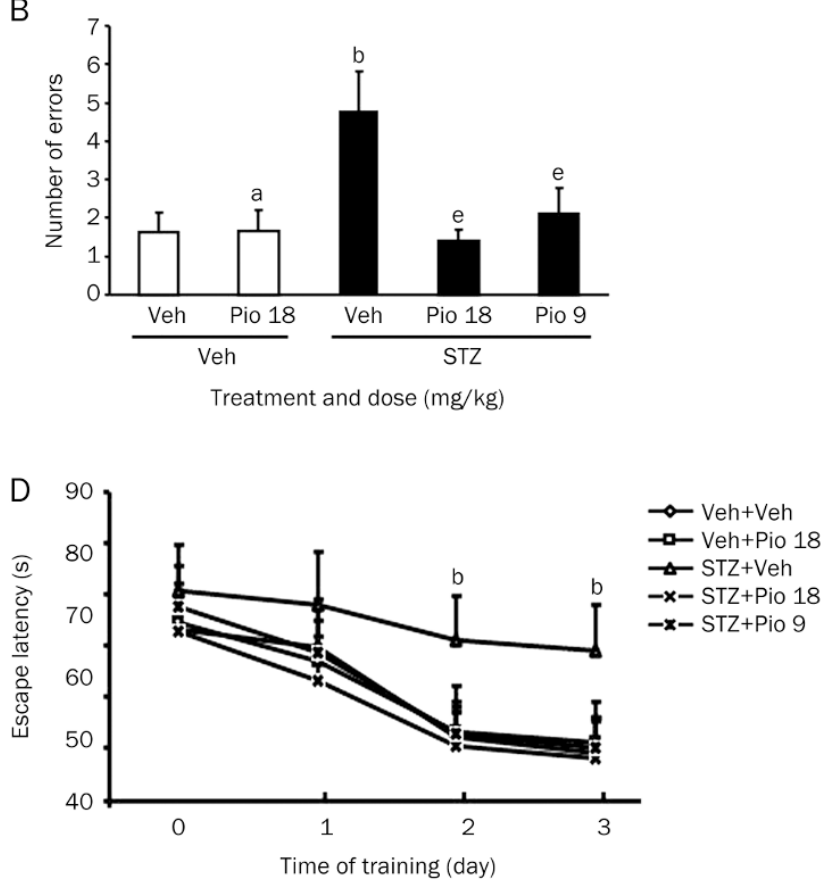

$\mathrm{F}$

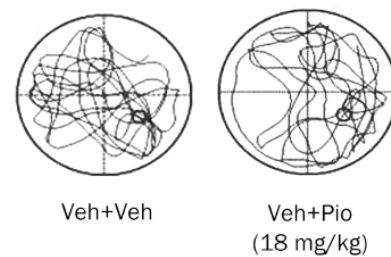

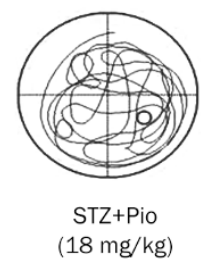

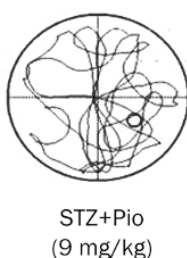

Figure 1. Chronic pioglitazone treatment attenuates memory impairment in STZ-induced diabetic mice. The mean latency time (A) and the number of errors (B) in the passive avoidance test and mean latency time during the visible-platform test (C), mean latency time during the hidden-platform test (D), the percentage of total time left in the target quadrant (E), and representative swim paths (F) during the spatial probe test are shown. D 0 indicates performance in the first trial, and subsequent points represent the average of all daily trials in the Morris water maze. Pioglitazone (18 mg/kg or 9 $\mathrm{mg} / \mathrm{kg}$ ) was administered orally once daily for 6 weeks. Values are expressed as the mean \pm SEM $(n=8-9)$. ${ }^{\mathrm{a}} P>0.05,{ }^{\mathrm{b}} P<0.05,{ }^{\mathrm{c}} P<0.01 \mathrm{vs}$ Veh+Veh. ${ }^{\mathrm{e}} P<0.05,{ }^{\mathrm{f}} P<0.01$ vs STZ+Veh.

age of time $[F(4,49)=18.539, P<0.001$, Figure $1 E]$ in the target quadrant compared to the Veh+Veh group. In contrast, STZinduced diabetic mice treated with pioglitazone $(18 \mathrm{mg} / \mathrm{kg}$ or $9 \mathrm{mg} / \mathrm{kg}$ ) showed significant increases in the index compared to the STZ+Veh group. The total distance swum during the probe trial test was not different among the groups (data not shown). No differences were observed in behavior tests between the Veh+Veh group and Veh+Pio $(18 \mathrm{mg} / \mathrm{kg})$ group.

Pioglitazone treatment prevents the brain $A \beta$ accumulation in STZ-induced diabetic mice

It has been confirmed that abnormal accumulation of $A \beta$ in the brain is an important cause of memory impairment ${ }^{[17]}$. To examine whether pioglitazone affects the $A \beta$ generation, we measured the $A \beta$ levels in the brain using ELISA assays. Figure $2 \mathrm{~A}$ and $2 \mathrm{~B}$ illustrated that the $A \beta_{1-40}$ and $A \beta_{1-42}$ content significantly increased by $35.5 \%$ and $28.5 \%$ in the hippocampus or by $22.0 \%$ and $25.5 \%$ in the cerebral cortex in mice in the STZ+Veh group compared to the age-matched $\mathrm{Veh}+\mathrm{Veh}$ group. Treatment with pioglitazone $(18 \mathrm{mg} / \mathrm{kg}$ or $9 \mathrm{mg} / \mathrm{kg}$ ) decreased the $\mathrm{A} \beta_{1-40}$ content by $29.1 \%$ and $21.1 \%$ in the hippocampus compared to that of the STZ+Veh group $[F(3,15)=11.488, P=0.001$, Figure $2 A]$, but decreases in the $\mathrm{A} \beta_{1-40}$ level in the cortex did not achieve statistical significance $[\mathrm{F}(3,15)=4.019, P=0.034$, Figure $2 \mathrm{~A}]$. Treatment with pioglitazone $(18 \mathrm{mg} / \mathrm{kg}$ and $9 \mathrm{mg} / \mathrm{kg})$ decreased the $A \beta_{1-42}$ content by $27.9 \%$ and $29.9 \%$ in the hippocampus $[\mathrm{F}(3,15)=5.046, P=0.017$, Figure $2 \mathrm{~B}]$ and by $18.2 \%$ and $17.1 \%$ in the cortex $[\mathrm{F}(3,15)=5.547$, 
A

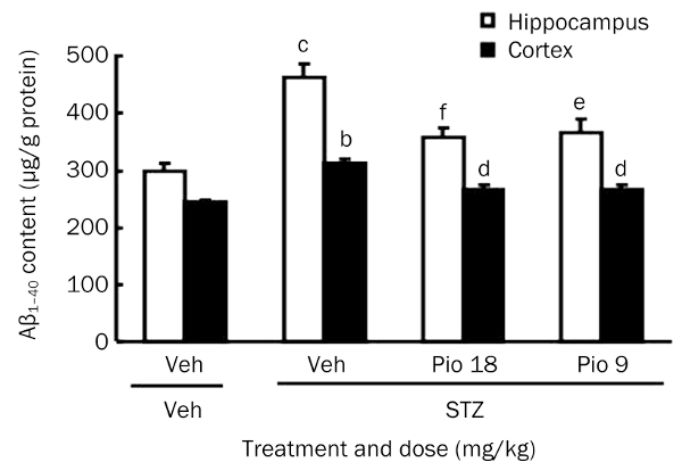

C

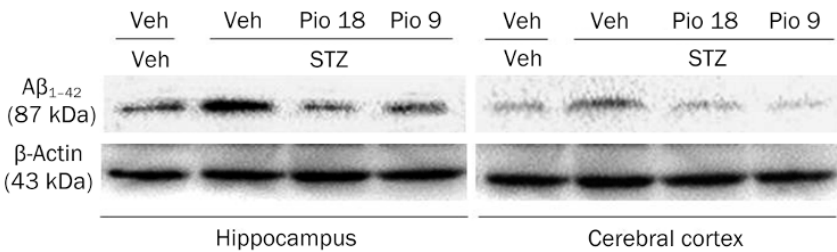

B

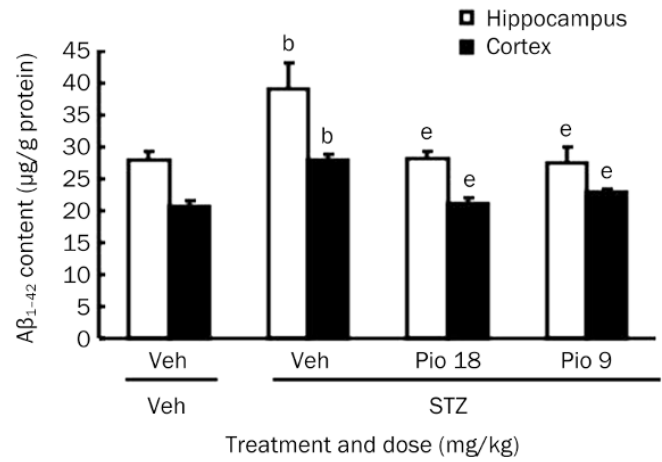

D

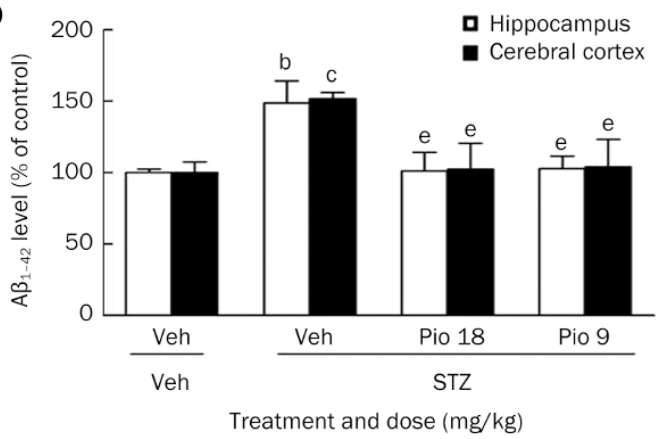

Figure 2. Pioglitazone treatment prevents brain $A \beta$ accumulation in STZ-induced diabetic mice. $A \beta_{1-40}(A)$ and $A \beta_{1-42}(B)$ levels in the hippocampus and cortex were assayed by ELISA. Representative immunoblots of $A \beta_{1-42}$ and $\beta$-actin (inner control) were obtained by Western blotting using the appropriate antibodies (C), and quantification of $A \beta_{1-42}$ is expressed as a proportion (in percentage) relative to the control (D). Values are expressed as the mean \pm SEM $(n=3-5) .{ }^{b} P<0.05,{ }^{c} P<0.01$ vs Veh+Veh. ${ }^{d} P>0.05,{ }^{e} P<0.05,{ }^{f} P<0.01$ vs STZ+Veh.

$P=0.013$, Figure 2B] compared with the STZ+Veh group. Furthermore, we detected $A \beta_{1-42}$, a more neurotoxic $A \beta$ species, in the hippocampus or cortex using Western blotting. This result was similar to the data that we found using ELISA assays (Figure $2 \mathrm{C}$ and 2D).

Pioglitazone treatment reduces brain APP and BACE1 levels in STZ-induced diabetic mice

$\mathrm{A} \beta$ is generated by secretase-dependent proteolysis of the $\beta$-amyloid precursor protein (APP) ${ }^{[22]}$. We measured the expression of APP by Western blotting. As shown in Figure 3, the expression of APP was significantly increased in the hippocampus and cortex of STZ-induced diabetic mice. Pioglitazone treatment $(18 \mathrm{mg} / \mathrm{kg}$ or $9 \mathrm{mg} / \mathrm{kg})$ significantly reversed the elevated APP levels in both the hippocampus $[F(3,11)=8.866, P=0.0063]$ and cortex $[F(3,11)=7.391, P=0.0108$, Figure $3 \mathrm{~A}$ and $3 \mathrm{~B}]$.

BACE1, also referred to as $\beta$-secretase, is a transmembrane aspartic proteinase responsible for cleaving the APP to generate the soluble ectodomain SAPP and its C-terminal fragment $\mathrm{CTF}$ and thus plays an important role in $\mathrm{A} \beta$ production ${ }^{[22]}$. To examine whether BACE1 contributed to the $A \beta$ production in STZ-induced diabetic mice, we determined the BACE1 levels by Western blotting. As shown in Figure 3, BACE1 levels significantly increased in the hippocampus and cortex of the mice in the STZ+Veh group compared with those of the mice in the Veh+Veh group. Treatment of STZ-induced diabetic mice with pioglitazone $(18 \mathrm{mg} / \mathrm{kg}$ or $9 \mathrm{mg} / \mathrm{kg}$ ) caused significant reductions in protein levels of BACE1 in both the hippocampus $[F(3,11)=8.467, P=0.0073]$ and the cortex $[F(3,11)=9.302$, $P=0.0055$, Figure $3 \mathrm{~A}$ and $3 \mathrm{C}]$.

Pioglitazone inhibits RAGE and NF-KB p65 in the brains of STZinduced diabetic mice

Activation of receptor for advanced glycation end products (RAGE) may play a role in neuronal damage and neuroinflammation associated with diabetes ${ }^{[23]}$. To determine the effect of pioglitazone on the brain RAGE levels of STZ-induced diabetic mice, we detected the expression of RAGE by Western blotting. Compared with those in the Veh+Veh group, the RAGE levels significantly increased in both the hippocampus and cortex in mice in the STZ+Veh group. Pioglitazone treatment $(18 \mathrm{mg} / \mathrm{kg}$ or $9 \mathrm{mg} / \mathrm{kg})$ significantly reversed the elevated RAGE levels in both the hippocampus $[\mathrm{F}(3,11)=9.344$, $P=0.0054]$ and cortex $[F(3,11)=9.477, P=0.0052$, Figure $4 \mathrm{~A}$ and 4B].

Because activation of RAGE triggers NF- $\mathrm{KB}$ signaling that regulates some gene expression, such as APP and BACE1 $1^{[24]}$, we used Western blotting to detect NF-kB p65 levels in the brain. Our data showed that NF-kB p65 levels significantly increased in both the hippocampus and cortex in STZ-induced diabetic mice compared to those in the Veh+Veh group 


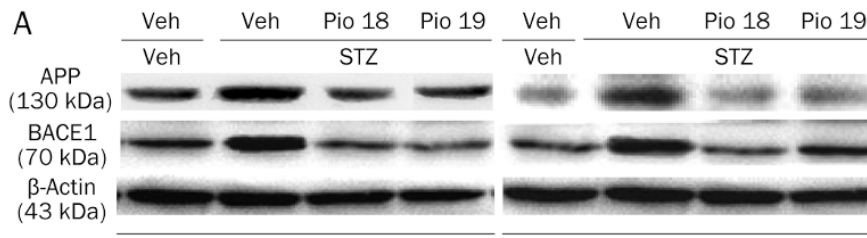

Hippocampus

Cerebral cortex

B

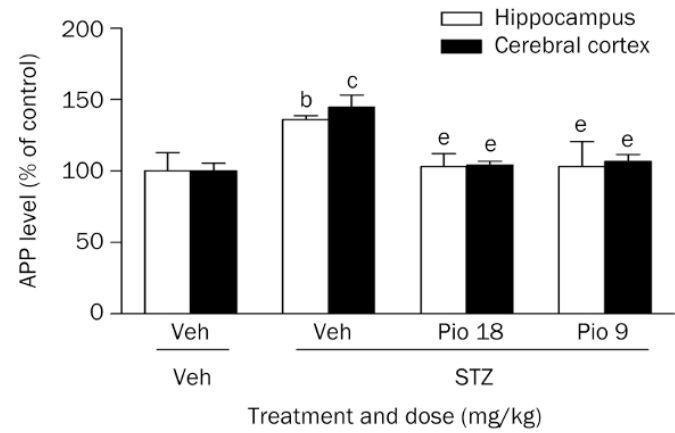

C

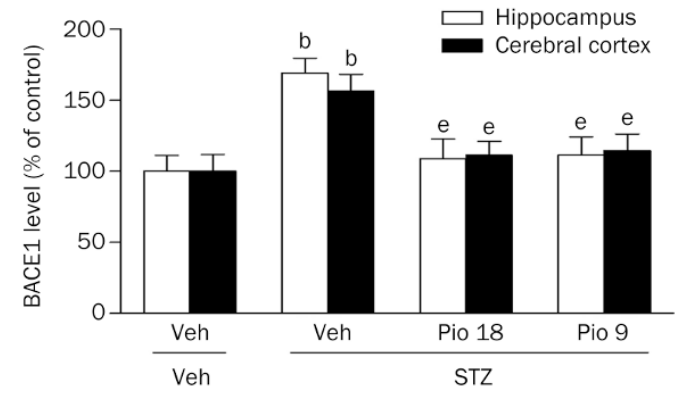

Treatment and dose $(\mathrm{mg} / \mathrm{kg})$

Figure 3. Pioglitazone treatment reduces brain APP and BACE1 levels in STZ-induced diabetic mice. The expressions of APP and BACE1 in the hippocampus and cortex were detected by Western blotting. Representative immunoblots of APP, BACE1, and $\beta$-actin (inner control) are displayed (A), and quantification of APP or BACE1 is expressed as a proportion (in percentage) of the control (B and $C)$. Values shown are expressed as the mean \pm SEM. $n=3 .{ }^{b} P<0.05,{ }^{\mathrm{C}} P<0.01$ vs Veh+Veh. ${ }^{\mathrm{e}} \mathrm{P}<0.05$ vs STZ+Veh.

$(P<0.01)$. Pioglitazone $(18 \mathrm{mg} / \mathrm{kg}$ or $9 \mathrm{mg} / \mathrm{kg})$ significantly decreased NF-kB p65 levels in the hippocampus $[\mathrm{F}(3,11)=8.677$, $P=0.0068]$ and cortex $[F(3,11)=9.992, P=0.0044$, Figure $4 \mathrm{~A}$ and $4 \mathrm{C}$ ] compared to those levels in the STZ+Veh group.

\section{Pioglitazone activates the brain PPARy in STZ-induced diabetic mice}

To determine if pioglitazone causes these effects through the activation of PPAR $\gamma$, we measured brain PPARY levels in the mice by Western blotting. As shown in Figure 5, the STZ-induced diabetic mice showed significant decreases in PPARY levels in both the hippocampus and cortex compared to the age-matched Veh+Veh group, and treatment with pioglitazone $(18 \mathrm{mg} / \mathrm{kg}$ or $9 \mathrm{mg} / \mathrm{kg})$ significantly reversed the decreased PPARY levels in the hippocampus $[\mathrm{F}(3,11)=8.029$, $P=0.0085]$ and cortex $[F(3,11)=13.88, P=0.0015$, Figure $5 \mathrm{~A}$ and

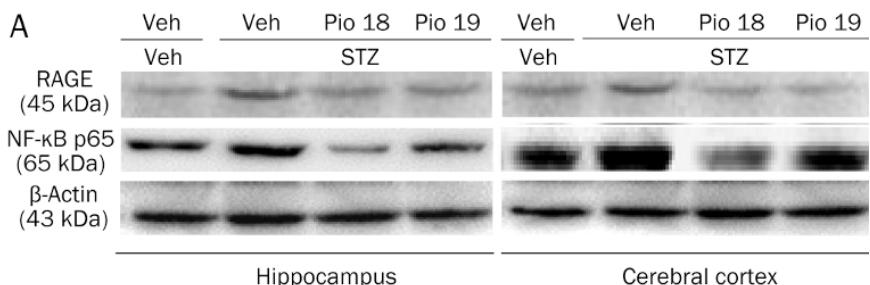

B

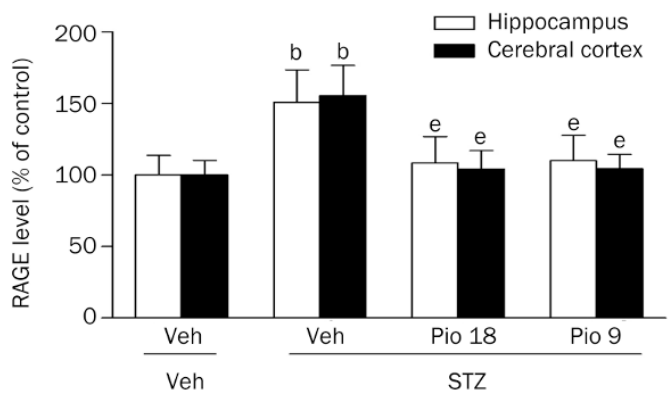

Treatment and dose $(\mathrm{mg} / \mathrm{kg})$

C

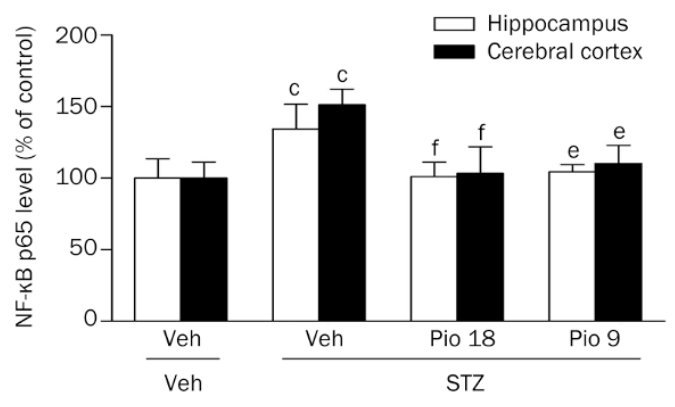

Treatment and dose $(\mathrm{mg} / \mathrm{kg})$

Figure 4. Pioglitazone suppresses RAGE and NF-kB p65 in the brain of STZ-induced diabetic mice. Representative immunoblots of RAGE, NFKB p65, and $\beta$-actin (inner control) were obtained by Western blotting using the appropriate antibodies in the hippocampus and cerebral cortex (A). Quantification of RAGE or NF-KB p65 is expressed as a proportion (in percentage) relative to the control $(B$ and $C)$. Values shown are expressed as the mean \pm SEM. $n=3 .{ }^{b} P<0.05,{ }^{c} P<0.01$ vs Veh+Veh. ${ }^{e} P<0.05$, ${ }^{\mathrm{f}} \mathrm{P}<0.01$ vs STZ+Veh.

5B], suggesting that the activation of PPARY by pioglitazone may be involved in improving amyloidogenesis and memory dysfunction in STZ-induced diabetic mice.

Pioglitazone does not beneficially influence body weight or blood glucose and insulin levels in STZ-induced diabetic mice

Compared with the age-matched Veh+Veh group, diabetic mice had lower body weights, higher levels of serum glucose $[F(4,49)=232.685, P<0.001$, Table 1] and lower levels of serum insulin $[F(4,49)=141.631, P<0.001$, Table 1]. We observed no significant changes in body weight or serum glucose and insulin levels after pioglitazone treatment for 6 weeks. We did not find any effects of pioglitazone treatment on body weight or serum glucose and insulin levels in the age-matched normal mice. 
A

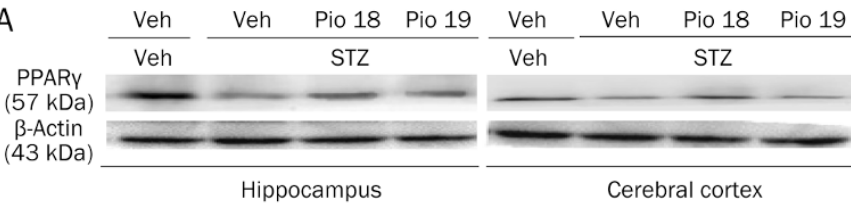

B

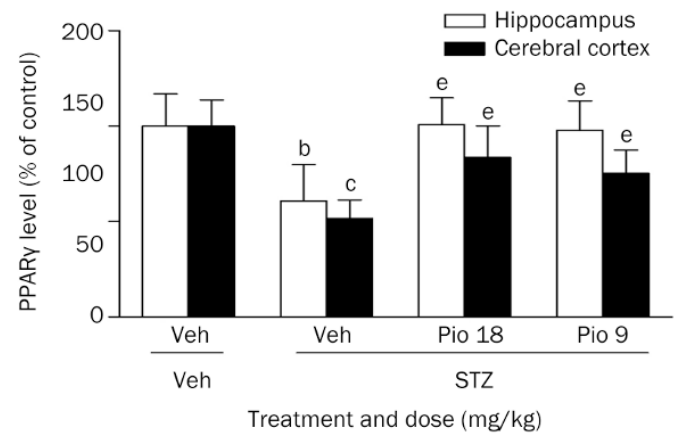

Figure 5. Pioglitazone activates brain PPARy in STZ-induced diabetic mice. PPARy of the hippocampus or cortex was assayed by Western blotting. Representative immunoblots of PPARy and $\beta$-actin (inner control) are displayed (A), and quantification of PPARy is expressed as a proportion (in percentage) of the control (B). Values shown are expressed as the mean \pm SEM. $n=3 .{ }^{b} P<0.05,{ }^{c} P<0.01$ vs Veh+Veh. ${ }^{e} P<0.05$ vs STZ+Veh.

Table 1. Effects of pioglitazone on body weight, serum glucose and insulin levels in STZ-induced diabetic mice (mean \pm SEM. $n=9-10$ ). ${ }^{a} P>0.05$, ${ }^{c} P<0.01$ vs Veh+Veh. ${ }^{\mathrm{d}} P>0.05$ vs STZ+Veh.

\begin{tabular}{lccr}
\hline \multicolumn{1}{c}{ Groups } & $\begin{array}{c}\text { Body weight } \\
\text { (g) }\end{array}$ & $\begin{array}{c}\text { Blood glucose } \\
(\mathrm{mmol} / \mathrm{L})\end{array}$ & $\begin{array}{c}\text { Serum insulin } \\
(\mathrm{mIU} / \mathrm{L})\end{array}$ \\
\hline Veh+Veh & $26.1 \pm 1.0$ & $4.95 \pm 0.52$ & $14.58 \pm 0.92$ \\
Veh+Pio $(18 \mathrm{mg} / \mathrm{kg})$ & $28.3 \pm 1.0^{\mathrm{a}}$ & $5.35 \pm 0.45^{\mathrm{a}}$ & $15.28 \pm 1.05^{\mathrm{a}}$ \\
STZ+Veh & $21.8 \pm 0.3^{\mathrm{c}}$ & $27.57 \pm 0.62^{\mathrm{c}}$ & $4.80 \pm 0.34^{\mathrm{c}}$ \\
STZ+Pio $(18 \mathrm{mg} / \mathrm{kg})$ & $21.2 \pm 0.4^{\mathrm{d}}$ & $26.44 \pm 1.26^{\mathrm{d}}$ & $4.54 \pm 0.51^{\mathrm{d}}$ \\
STZ+Pio $(9 \mathrm{mg} / \mathrm{kg})$ & $20.7 \pm 0.2^{\mathrm{d}}$ & $25.80 \pm 1.81^{\mathrm{d}}$ & $4.27 \pm 0.37^{\mathrm{d}}$ \\
\hline
\end{tabular}

\section{Discussion}

Patients with T1DM, which is caused by the destruction of insulin-producing $\beta$ cells of the pancreas, are susceptible to complications, such as deficits of cognition, psychomotor function, learning and memory ${ }^{[25-27]}$. Although several factors such as vascular complications, metabolic disturbances, and the release of free radicals are implicated, the mechanisms underlying these complications are not fully understood. In our study using an experimental T1DM animal model, STZinduced diabetic mice, were characterized by hyperglycemia and hypoinsulinemia; these mice demonstrated marked impairment in cognitive function, which was coupled with marked increases in $A \beta_{1-40}$ and $A \beta_{1-42}$ levels in the brain. Chronic treatment with pioglitazone, a PPAR $\gamma$ agonist, significantly ameliorated cognitive deficits and produced significant decreases in $A \beta_{1-40}$ and $A \beta_{1-42}$ levels via activation of PPARY, which affected NF-kB p65, APP, BACE1, and RAGE in the brain instead of its regulation of hyperglycemia or hyperinsulinemia in STZ-induced mice.

Several publications have confirmed that abnormal accumulation of $A \beta$ in the brain is associated with cognitive dysfunc$\operatorname{tion}^{[28,29]}$. The mice injected with a single high dose of STZ, a nongenetic rodent model mimicking human T1DM, displayed memory impairment, which was demonstrated by decreases in the step-through latency and increases in the number of errors in the passive avoidance test, as well as decreases in the percentage of time spent in the target quadrant in the MWM test, accompanied by elevations of $A \beta_{1-40}$ and $A \beta_{1-42}$ levels in the brain. The accumulation of $A \beta$, especially $A \beta_{1-42}$, in the brain may initiate pathogenic cascades mediating neurovascular and neuronal dysfunctions associated with the development of cerebral $\beta$-amyloidosis and cognitive decline in patients with diabetes ${ }^{[22,30]}$. A $\beta$ originates from proteolysis of the APP by the sequential enzymatic actions of BACE1, a $\beta$-secretase, and $\gamma$-secretase.

Overexpression of APP and BACE1 was recently reported in a diabetic animal model, which is one of the reasons for $A \beta$ accumulation in the brain ${ }^{[11,31,32]}$. Both APP and the BACE1 promoter contain a binding site for NF- $\mathrm{KB}^{[24,33]}$, which is a representative transcription factor activated by RAGE-ligand interactions ${ }^{[23,32]}$. Hyperglycemia, a consequence of diabetes, enhances the formation of advanced glycation end products (AGEs), senescent protein derivatives that result from the auto-oxidation of glucose and fructose ${ }^{[34]}$. Binding of AGEs to the receptor for AGEs (RAGE) activates intracellular signaling processes, such as the NF-kB pathway, thus mediating proinflammatory AGE effects. The formation and accumulation of AGEs have been known to progress at an accelerated rate in diabetes ${ }^{[35,36]}$. Activation of the AGEs/RAGE axis, as a result of hyperglycemia, drives the upregulation of the APP, and BACE1 for $\mathrm{A} \beta$ production via NF- $\mathrm{KB}$ activation and results in $A \beta$ accumulation in diabetic animals. In addition, the increasing AGEs or $A \beta$ continued binding RAGE, which, in turn, caused NF-KB activation, thereby triggering a positive feedback loop in which RAGE expression is upregulated and thus enhances the binding capacity of the AGEs and $A \beta$ ligands ${ }^{[37]}$. As expected, activation of the NF-KB pathway, which is characterized by the elevation of NF-KB p65 protein level, and its mediated-upregulation of APP, BACE1 and RAGE were observed in STZ-induced diabetic mice.

The synthetic TZDs, such as pioglitazone and rosiglitazone, which serve as PPARY agonists, are widely prescribed for the treatment of T2DM and have also been shown to be efficacious in a number of CNS disease models ${ }^{[38]}$. The nuclear receptor subtype PPARY is a ligand-activated transcription factor whose biological actions regulate glucose and lipid metabolism and suppress inflammatory gene expression. Agonists of this receptor represent an attractive therapeutic target for diabetes-associated cognitive decline. Recently, pioglitazone was shown to be efficacious in treating cognitive deficits in a mouse model of T2DM; pioglitazone treatment contributes to either decreases in $A \beta$ levels in the brain or the attenuation 
of hyperglycemia and hypoinsulinemia ${ }^{[20]}$. However, little was known about whether its CNS effect is independent of or secondary to the regulation of hyperglycemia and hypoinsulinemia in T2DM. In STZ-induced diabetic mice, no effects of pioglitazone on hyperglycemia and hypoinsulinemia were observed; and interestingly, it still showed similar CNS effects with mouse model of T2DM. Significant low expression of PPARY was observed in both the hippocampus and the cortex of the diabetic mice, and chronic treatment with pioglitazone reversed the decreased PPARY levels, indicating enhancement of its activity. Pascual et al recently provided compelling evidence that PPARY blocks NF-KB-dependent gene expression through corepressor interference ${ }^{[39]}$. Thus, it is reasonable that decreases in the expression of APP, BACE1, or RAGE resulted from PPAR $\gamma$-mediated inactivation of NF-KB in the brains of diabetic mice treated with pioglitazone.

In conclusion, we have demonstrated that chronic administration of pioglitazone improves learning performance in STZinduced diabetic mice. This CNS effect results from alleviation of $A \beta$ burden via activation of PPARY in the brain rather than attenuation of hyperglycemia and hypoinsulinemia in the periphery. Our study has important implications for patients with T1DM, suggesting a potential role for PPARY agonists as an adjuvant therapy for the prevention and treatment of diabetes-associated cognition impairment.

\section{Acknowledgements}

This work was supported, in part, by the Natural Science Foundation of Anhui Province, China (№ 1208085MH164).

\section{Author contribution}

Li-ping LIU and Tian-hua YAN contributed to the study design and performed experiments; Li-ying JIANG, Wei HU, Chao WANG, and Meng HU participated in behavioral tests and Western blotting analysis; Qian ZHANG, Yan LONG, Jiang-qing WANG, Yong-qi LI, and Mei HU participated in ELISA assays and biochemical analysis; Hao HONG initiated the project and participated in the design of the studies; and all authors contributed to the data analysis.

\section{References}

1 Biessels GJ, Deary IJ, Ryan CM. Cognition and diabetes: a lifespan perspective. Lancet Neurol 2008; 7: 84-90.

2 Kodl CT, Seaquist ER. Cognitive dysfunction and diabetes mellitus. Endocr Rev 2008; 29: 494-511.

3 Wrighten SA, Piroli GG, Grillo CA, Reagan LP. A look inside the diabetic brain: contributors to diabetes-induced brain aging. Biochim Biophys Acta 2009; 1792: 444-53.

4 Biessels GJ, Kamal A, Urban IJ, Spruijt BM, Erkelens DW, Gispen WH. Water maze learning and hippocampal synaptic plasticity in streptozotocin-diabetic rats: effects of insulin treatment. Brain Res 1998; 800: 125-35.

5 Biessels GJ, Cristino NA, Rutten GJ, Hamers FP, Erkelens DW, Gispen WH. Neurophysiological changes in the central and peripheral nervous system of streptozotocin-diabetic rats: course of development and effects of insulin treatment. Brain 1999; 122: 757-68.

6 Sima AA, Li ZG. The effect of C-peptide on cognitive dysfunction and hippocampal apoptosis in type 1 diabetic rats. Diabetes 2005; 54 : 1497-505.

7 Sima AA, Zhang W, Muzik O, Kreipke CW, Rafols JA, Hoffman WH. Sequential abnormalities in type 1 diabetic encephalopathy and the effects of C-Peptide. Rev Diabet Stud 2009; 6: 211-22.

8 Sims-Robinson C, Kim B, Rosko A, Feldman EL. How does diabetes accelerate Alzheimer disease pathology? Nat Rev Neurol 2010; 6 : 551-9.

9 Peila R, Rodriguez BL, Launer LJ, Honolulu-Asia Aging Study. Type 2 diabetes, APOE gene, and the risk for dementia and related pathologies: The Honolulu-Asia Aging Study. Diabetes 2002; 51: 1256-62.

10 Valente T, Gella A, Fernàndez-Busquets X, Unzeta M, Durany N. Immunohistochemical analysis of human brain suggests pathological synergism of Alzheimer's disease and diabetes mellitus. Neurobiol Dis 2010; 37: 67-76.

11 Li ZG, Zhang W, Sima AA. Alzheimer-like changes in rat models of spontaneous diabetes. Diabetes 2007; 56: 1817-24.

12 Hong H, Liu LP, Liao JM, Wang TS, Ye FY, Wu J, et al. Downregulation of LRP1 at the blood-brain barrier in streptozotocin-induced diabetic mice. Neuropharmacology 2009; 56: 1054-9.

13 Jolivalt CG, Hurford R, Lee CA, Dumaop W, Rockenstein E, Masliah E. Type 1 diabetes exaggerates features of Alzheimer's disease in APP transgenic mice. Exp Neurol 2010; 223: 422-31.

14 Liu Y, Liu H, Yang J, Liu X, Lu S, Wen T, et al. Increased amyloid betapeptide (1-40) level in brain of streptozotocin-induced diabetic rats. Neurosci 2008; 153: 796-802.

15 Qu ZS, Tian Q, Zhou XW, Wang XC, Wang Q, Zhang Q, et al. Alteration of beta-amyloid and glutamate transporter in the brain of diabetes rats and the underlying mechanism. Zhongguo Yi Xue Ke Xue Yuan Xue Bao 2005; 27: 708-11.

16 Shuli S, Yongmei Z, Zhiwei Z, Zhijuan J. beta-Amyloid and its binding protein in the hippocampus of diabetic mice: effect of APP17 peptide. Neuroreport 2001; 12: 3317-9.

17 Takeda S, Sato N, Uchio-Yamada K, Sawada K, Kunieda T, Takeuchi D, et al. Diabetes-accelerated memory dysfunction via cerebrovascular inflammation and Abeta deposition in an Alzheimer mouse model with diabetes. Proc Natl Acad Sci U S A 2010; 107: 7036-41.

18 Sood V, Colleran K, Burge MR. Thiazolidinediones: a comparative review of approved uses. Diabetes Technol Ther 2000; 2: 429-40.

19 Nicolakakis N, Hamel E. The nuclear receptor PPARgamma as a therapeutic target for cerebrovascular and brain dysfunction in Alzheimer's disease. Front Aging Neurosci 2010; 2: 21-6.

20 Jiang LY, Tang SS, Wang XY, Liu LP, Long Y, Hu M, et al. PPARY agonist pioglitazone reverses memory impairment and biochemical changes in a mouse model of type 2 diabetes mellitus. CNS Neurosci Ther 2012; 18: 659-66.

21 Morris R. Developments of a water-maze procedure for studying spatial learning in the rat. J Neurosci Methods 1984; 11: 47-60.

22 Karran E, Mercken M, De Strooper B. The amyloid cascade hypothesis for Alzheimer's disease: an appraisal for the development of therapeutics. Nat Rev Drug Discov 2011; 10: 698-712.

23 Rincon N, Xu K, Li J, Martinez JA, Hernandez MA, Singh GS, et al. Blockade of receptor for advanced glycation end products in a model of type 1 diabetic leukoencephalopathy. Diabetes 2012. DOI: 10.2337/db12-0317.

24 Chami L, Buggia-Prévot V, Duplan E, Delprete D, Chami M, Peyron $\mathrm{JF}$, et al. Nuclear factor- $\mathrm{KB}$ regulates $\beta \mathrm{APP}$ and $\beta$ - and $\mathrm{y}$-secretases differently at physiological and supraphysiological $A \beta$ concentrations. J Biol Chem 2012; 287: 24573-84.

25 Brands AM, Kessels RP, Hoogma RP, Henselmans JM, van der Beek 
Boter JW, Kappelle LJ, et al. Cognitive performance, psychological well-being, and brain magnetic resonance imaging in older patients with type 1 diabetes. Diabetes 2006; 55: 1800-6.

26 Hannonen R, Komulainen J, Eklund K, Tolvanen A, Riikonen R, Ahonen T. Verbal and academic skills in children with early-onset type 1 diabetes. Dev Med Child Neurol 2010; 52: e143-7.

27 Munshi M, Grande L, Hayes M, Ayres D, Suhl E, Capelson R, et al. Cognitive dysfunction is associated with poor diabetes control in older adults. Diabetes Care 2006; 29: 1794-9.

28 Glabe CG. Common mechanisms of amyloid oligomer pathogenesis in degenerative disease. Neurobiol Aging 2006; 27: 570-5.

29 Ballard C, Gauthier S, Corbett A, Brayne C, Aarsland D, Jones E. Alzheimer's disease. Lancet 2011; 377: 1019-31.

30 Han W, Li C. Linking type 2 diabetes and Alzheimer's disease. Proc Natl Acad Sci U S A 2010; 107: 6557-8.

31 Jung SW, Han OK, Kim SJ. Increased expression of $\beta$ amyloid precursor gene in the hippocampus of streptozotocin-induced diabetic mice with memory deficit and anxiety induction. Neural Transm 2010; 117: 1411-8.

32 Guglielmotto M, Aragno M, Tamagno E, Vercellinatto I, Visentin S, Medana $\mathrm{C}$, et al. AGEs/RAGE complex upregulates BACE1 via NF-kappaB pathway activation. Neurobiol Aging 2012; 33: 196.e13-27.
33 Bourne KZ, Ferrari DC, Lange-Dohna C, Rossner S, Wood TG, PerezPolo JR. Differential regulation of BACE1 promoter activity by nuclear factor-B in neurons and glia upon exposure to beta-amyloid peptides. J Neurosci Res 2007; 85: 1194-204.

34 Bucala R, Cerami A. Advanced glycosylation: chemistry, biology, and implications for diabetes and aging. Adv Pharmacol 1992; 23: 1-34.

35 Thorpe SR, Baynes JW. Maillard reaction products in tissue proteins: New products and new perspectives. Amino Acids 2003; 25: 275-81.

36 Yamagishi S, Matsui T, Nakamura K. Kinetics, role and therapeutic implications of endogenous soluble form of receptor for advanced glycation end products (sRAGE) in diabetes. Curr Drug Targets 2007; 8: 1138-43.

37 Liu LP, Hong H, Liao JM, Wang TS, Wu J, Chen SS, et al. Upregulation of RAGE at the blood-brain barrier in streptozotocin-induced diabetic mice. Synapse 2009; 63: 636-42.

38 Mandrekar-Colucci S, Landreth GE. Nuclear receptors as therapeutic targets for Alzheimer's disease. Expert Opin Ther Target 2011; 15: 1085-97.

39 Pascual G, Fong AL, Ogawa S, Gamliel A, Li AC, Perissi V, et al. A SUMOylation-dependent pathway mediates transrepression of inflammatory response genes by PPAR-gamma. Nature 2005; 437: 759-63. 